\title{
OPTIMAL SEASONAL VOLTAGE CONTROL IN RURAL DISTRIBUTION NETWORKS WITH DISTRIBUTED GENERATORS
}

\author{
Jordan Radosavljević — Miroljub Jevtić — Dardan Klimenta *
}

\begin{abstract}
This paper proposes a procedure for determining the optimal tap changer positions of off-voltage tap changing transformers in radial rural distribution networks in presence of distributed generators (DGs). The procedure is based on spatial network decomposition and as well as bringing down a branchy LV network to an equivalent line. Optimal voltage module values of PV nodes in the optimal seasonal control plan are determined by the application of a genetic algorithm. The proposed procedure is examined in two real distribution networks: a radial 33-node network with 11 DGs modelled as PQ nodes and a radial 40-node network with three DGs in total, two of which are modelled as PV nodes and one modelled as a PQ node.
\end{abstract}

K e y w ords: distribution network, voltage control, distributed generator (DG), off-voltage tap changing transformer (OVTCT), genetic algorithm (GA)

\section{INTRODUCTION}

Distributed generators can have a significant influence on the power flow and voltage conditions in a distribution network [1-8]. Voltage control is one of the most important power functions in distribution networks with DGs. Basic voltage control resources in distribution networks are under-load tap changing transformers (ULTCTs) and off-voltage tap changing transformers (OVTCTs). References [9-16] examine the impact of DGs on the voltage control resources and at the same time suggest various procedures required for their mutual coordination aiming to achieve the optimal voltage control. The ULTCT are dealt with in most cases.

Generally the OVTCTs are the only control resources in rural distribution networks. In such cases, the voltage control can be regarded as one of the segments within the optimal distribution network exploitation plan over a certain period (season). Solving this problem would imply determining the optimal tap changer setting positions on the OVTCTs, while the aim of the control would be achieving a minimal voltage deviation and/or power loss in the distribution network according to the predicted seasonal power diagram of consumers and DGs.

The impact of DGs on the course of solving and the solution to this problem depends on their size (power), location and type. The ability of a DG to participate in the voltage control process in a distribution network is highly dependant on the connection type and operation mode. There are three possible typical cases [17]:

1) The DG is located near a large load and it is designated to supply this load, with constant active and reactive power output. In this case, the impact of the DG is brought down to decreasing of the total power load at the connection point. The node at which the DG is connected can be represented as a PQ node, whereas the DG can be modelled as a negative power load.

2) The DG injects active power with an approximately constant power factor. The voltage at the DG connection point increases together with the increase of the active power of the DG. In this case too, the node at which the DG is connected can be represented as a PQ node, whereas the DG can be modelled as a negative power load.

3) The DG injects power with specific voltage at the connection point. This DG controls the reactive power injection at the connection point, therefore controlling the voltage as well. The node at which such a DG is connected must be treated as a PV node. Their participation in the voltage control of the distribution network can be significant

A procedure for determining the optimal seasonal voltage control plan in radial (rural) distribution networks with DGs is presented in this paper. The procedure is based on the spatial decomposition principle of the voltage control problem. [18].

\section{OPTIMAL SEASONAL VOLTAGE CONTROL}

Figure 1 shows a typical radial rural distribution network. It consists of a medium-voltage (MV) node $(35 \mathrm{kV})$ - the feed point of the network, an MV/MV $(35 / 10 \mathrm{kV} / \mathrm{kV})$ supply transformer, an MV network $(10 \mathrm{kV})$ and several $\mathrm{MV} / \mathrm{LV}$ transformers and their belonging $\mathrm{LV}$ networks $(0.4 \mathrm{kV})$ or $\mathrm{LV}$ feeders. The MV/MV and all distribution $\mathrm{MV} / \mathrm{LV}$ transformers are OVTCT. The consumers and DGs are represented as PQ nodes.

The voltage control activity performed by the MV/MV transformer covers the whole area "behind" (MV net-

\footnotetext{
* Faculty of Technical Sciences, Priština University in Kosovska Mitrovica, Kneza Miloša 7, 38220 Kosovska Mitrovica, Serbia, radjor73@yahoo.com
} 


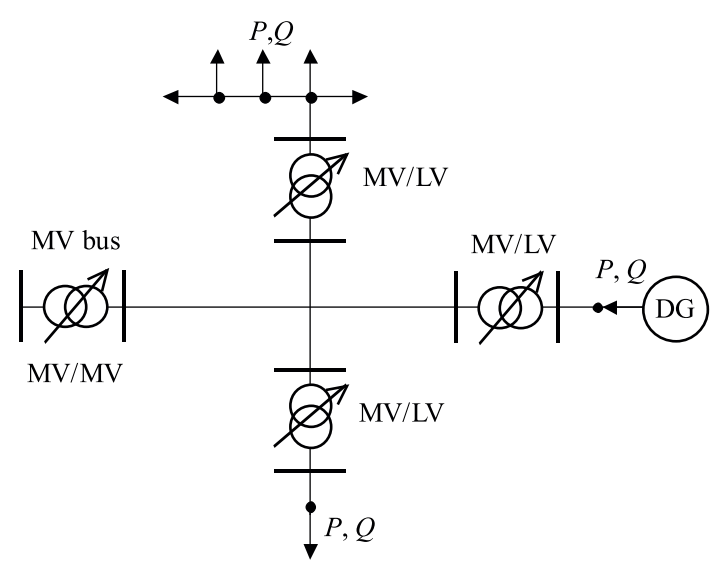

Fig. 1. Radial distribution network

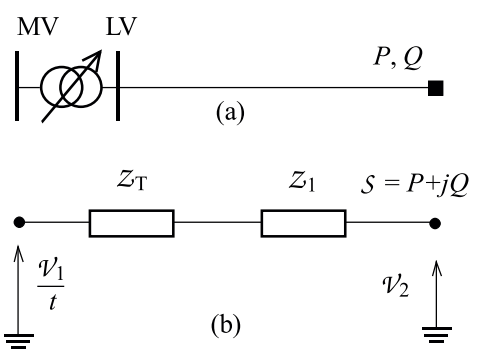

Fig. 2. (a) - one-phase model and (b) - the equivalent scheme of a simple radial system

work, MV/LV transformers and consequently their LV networks). However, due to the radial structure of the network, control activities of a $\mathrm{MV} / \mathrm{LV}$ transformer do not have any influence on the LV network voltages which are supplied from other MV/LV transformers. This represents the foundation of the spatial decomposition of the voltage control.

Therefore, solving the optimal seasonal voltage control problem can be carried out in two stages. The first stage consists of determining the optimal tap changer positions of the MV/LV transformers, while the second one implies determining the optimal tap changer position of the power supply MV/MV transformer.

\subsection{The first stage of the optimal seasonal volt- age control (optimal tap changer positions of the MV/LV transformers)}

As already mentioned, due to the radial character of the distribution network, voltage control on the MV/LV transformers influences the voltage consumers (as well as the DGs which are modelled as "negative loads") connected to the transformer, but it does not have any influence on the voltage consumers and DGs connected to the other transformers. This enables an independent determination of the optimal tap changer positions for each $\mathrm{MV} / \mathrm{LV}$ distribution transformer. For the given power of the LV consumer, the voltage of the MV bus of the $\mathrm{MV} / \mathrm{LV}$ transformer is mainly constant in regard to the tap changer position of the transformer. Accordingly, the optimal tap changer position can be determined as the function of the consumer power (ie the DG) on the LV side of the transformer, the voltage on the MV bus of the transformer and the desired voltage value on the LV side of the transformer. The issue of choosing the desired voltage value can be regarded as the optimization criterion. However, the optimal operation of the system is implicitly determined by the nominal voltage values. The aim of the seasonal voltage control is to keep consumer voltages as approximate to nominal values as possible.

Figure 2 shows the part of the distribution network consisting of the $\mathrm{MV} / \mathrm{LV}$ transformer, line and consumer ( $i e$ the DG). The parameters and values in this figure are given in per-unit system $(\mathrm{pu})$ and:

$\mathcal{Z}_{r}=R_{T}+j X_{T}$ - transformer impedance

$\mathcal{Z}_{l}=R_{l}+j X_{l}-$ line impedance

$\mathcal{V}_{1}$ - voltage phasor of the MV transformer buses

$\mathcal{V}_{2}$ - voltage phasor at the line end

$\mathcal{S}=P+j Q-$ complex injected power

$t=1+n \Delta t-$ non-nominal transmission ratio

$n$ - tap changer position

$\Delta t$ - step between tap changer positions ( $\mathrm{pu}$ ).

The voltage values of the network nodes for the given power of the consumer and the DG are determined by the power flow calculation [17]. Assuming that the value of $V_{1}$ is approximately constant, the relation between the voltage modules $V_{1}$ and $V_{2}$ is as follows

$$
\left(\frac{V_{1}}{t}\right)^{2}=\left(V_{2}+\frac{P R+Q X}{V_{2}}\right)^{2}+\left(\frac{P X-Q R}{V_{2}}\right)^{2}
$$

where $R=R_{T}+R_{l}$ and $X=X_{T}+X_{l}$. The non-nominal transmission ratio $t$ is calculated from equation (1), for the specified voltage value $V_{2}$

$$
t=\frac{V_{1}}{\sqrt{\left(V_{2}+\frac{P R+Q X}{V_{2}}\right)^{2}+\left(\frac{P X-Q R}{V_{2}}\right)^{2}}}
$$

It is now possible to calculate the optimal tap changer position of the transformer

$$
N=\frac{t-1}{\Delta t}
$$

The real tap changer position $\left(n_{r}\right)$ is determined as the closest integer value from the range of the defined discrete values, based on the obtained value $n$ according to equation (3). At most $\mathrm{MV} / \mathrm{LV}$ distribution transformers this range is $n_{r}=(-2,0,1.2)$. If the obtained value for $n$ is bigger than the maximum value from the defined range, the maximum value from the range $i e n_{r}=n_{\max }$ is adopted as valid. In case the obtained value is smaller than the minimum value from the defined range, the minimum value $n_{r}=n_{\min }$ is adopted as valid for the tap changer position. Since the real (adopted) position of the tap changer $n_{r}$ is different from the calculated value $n$, the real value of the voltage $V_{2}$ is obtained by square root equation (1) at $V_{2}$ or by the power flow calculation in the whole distribution network, whereas the value of the non-nominal transmission ratio is $t=1+\Delta t n_{r}$. 


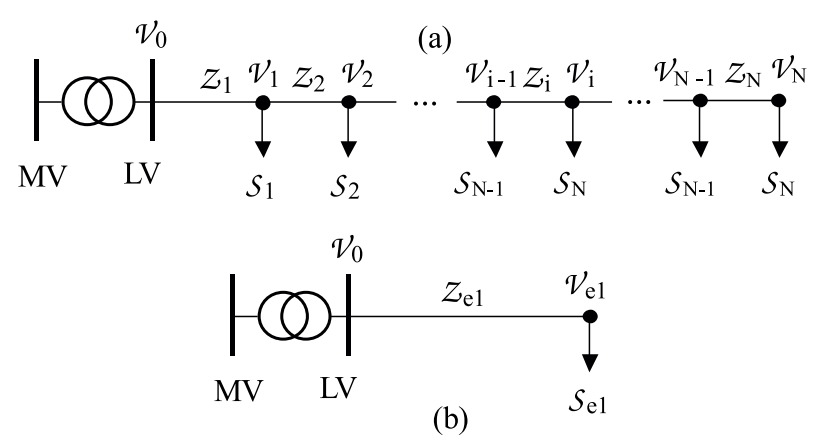

Fig. 3. (a) - radial LV line, and (b) - equivalent line model of the radial $\mathrm{LV}$ line

\subsubsection{Seasonal power diagram}

Since the consumers load (power, current) and the DGs power output are not constant during the day, month or year, it is necessary to determine their representative values over the given period. One of the possible approaches is the medium power model. Depending on the shape, annual power diagrams of consumers and DG, they can be divided into seasons, usually two with the same or different durations. The seasonal power represents the mean value of the power segments which account for a season. In a general case, different power diagrams can be divided into different seasons. However, considering the fact that the seasonal voltage control in this paper implies a simultaneous harmonization of the tap changer positions of the MV/MV supply transformer and all MV/LV transformers, it is necessary that the seasons are the same (coinciding) for the whole system. It is possible to meet this demand only in case the following assumptions can be applied:

(1) All consumers in rural distribution networks are alike $i e$ they have approximately the same normalized annual power diagrams;

(2) The DGs connected to the distribution network have similar annual power diagrams.

\subsubsection{Equivalent LV network model}

In order to apply the described procedure for determining the optimal tap changer position of the $\mathrm{MV} / \mathrm{LV}$ OVTCT, it is necessary to transform the LV network into the equivalent line model, as shown in Fig. 2. The principle of equal voltage sags and the principle of equal power losses in the real (LV network) and equivalent (line model) systems are used for determining the equivalent line model impedance and equivalent injection power at the end of the equivalent line model. Figure 3 shows the radial LV line with $N$ nodes and sections as well as the equivalent line model. The section $i$ impedance, the injection power and the voltage at the node $i$ are marked with $\mathcal{Z}_{i}, \mathcal{S}_{i}$ and $\mathcal{V}_{i}$, respectively.

The equivalent line model of $M$ radial LV lines, connected to the $\mathrm{LV}$ buses of the $\mathrm{MV} / \mathrm{LV}$ transformers (Fig. 4) can be determined based on the equal power loss principle.
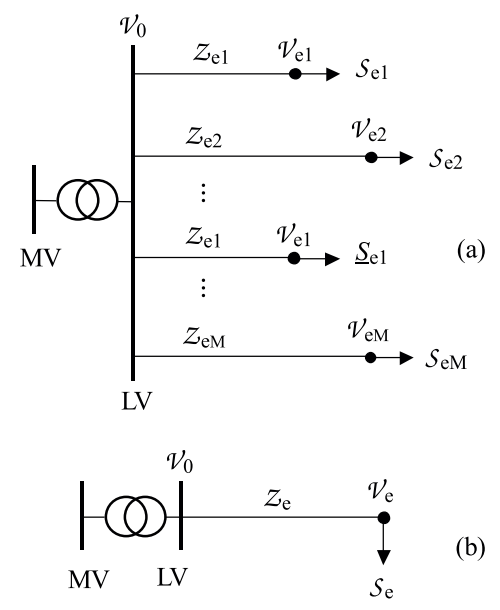

Fig. 4. (a) - several LV lines connected to the LV transformer buses and (b) - the equivalent line model

The equivalent line model impedance $\mathcal{Z}_{e 1}$ is determined according to the principle of equal voltage sags

$$
\begin{aligned}
& \mathcal{Z}_{e 1}= \\
& \frac{\mathcal{Z}_{1} \frac{\mathcal{S}_{1}^{*}}{\mathcal{V}_{1}^{*}}+\left(\mathcal{Z}_{1}+\mathcal{Z}_{2}\right) \frac{\mathcal{S}_{2}^{*}}{\mathcal{V}_{2}^{*}}+\cdots+\left(\mathcal{Z}_{1}+\cdots+\mathcal{Z}_{N}\right) \frac{\mathcal{S}_{N}^{*}}{\mathcal{V}_{N}^{*}}}{\sum_{i=1}^{N} \frac{\mathcal{S}_{i}^{*}}{\mathcal{V}_{i}^{*}}}
\end{aligned}
$$

The voltage at the end of the equivalent line model is the following

$$
\mathcal{V}_{e 1}=\mathcal{V}_{0}-\mathcal{Z}_{e 1} \sum_{i=1}^{n} \frac{\mathcal{S}_{i}^{*}}{\mathcal{V}_{i}^{*}}
$$

Whereas the injection power at the end of the equivalent line model is

$$
\mathcal{S}_{e 1}=\mathcal{V}_{e 1} \sum_{i=1}^{N} \frac{\mathcal{S}_{i}}{\mathcal{V}_{i}}
$$

The node voltages in the per unit system are close to 1 , and therefore equations (4) and (6) can be simplified

$$
\begin{gathered}
\mathcal{Z}_{e 1}=\frac{\mathcal{Z}_{1} \mathcal{S}_{1}+\left(\mathcal{Z}_{1}+\mathcal{Z}_{2}\right) \mathcal{S}_{2}+\cdots+\left(\mathcal{Z}_{1}+\cdots+\left.\right|_{N}\right) \mathcal{S}_{N}}{\sum_{i=1}^{N} \mathcal{S}_{i}} \\
\mathcal{S}_{e 1}=\sum_{i=1}^{N} \mathcal{S}_{i} \\
\mathcal{Z}_{e}=\frac{\mathcal{Z}_{e 1}\left|\frac{\mathcal{S}_{e 1}^{*}}{\mathcal{V}_{e 1}^{*}}\right|^{2}+\mathcal{Z}_{e 2}\left|\mathcal{S}_{e 2}^{*}\right|_{\mathcal{V}_{e 2}^{*}}^{2}+\cdots+\mathcal{Z}_{e M}\left|\frac{\mathcal{S}_{e M}^{*}}{\mathcal{V}_{e M}^{*}}\right|^{2}}{\left|\sum_{j=1}^{M} \frac{\mathcal{S}_{e j}^{*}}{\mathcal{V}_{e j}^{*}}\right|^{2}}
\end{gathered}
$$

The previous equation can be simplified

$$
\mathcal{Z}_{e}=\frac{\mathcal{Z}_{e 1}\left|\mathcal{S}_{e 1}\right|^{2}+\mathcal{Z}_{e 2}\left|\mathcal{S}_{e 2}\right|^{2}+\cdots+\mathcal{Z}_{e M}\left|\mathcal{S}_{e M}\right|^{2}}{\left|\sum_{j=1}^{M} \mathcal{S}_{e j}\right|^{2}}
$$

Therefore, the injection power at the end of the line model is now

$$
\mathcal{S}_{e}=\sum_{j=1}^{M} \mathcal{S}_{e j}
$$

The terms used in all the previous equations are the 


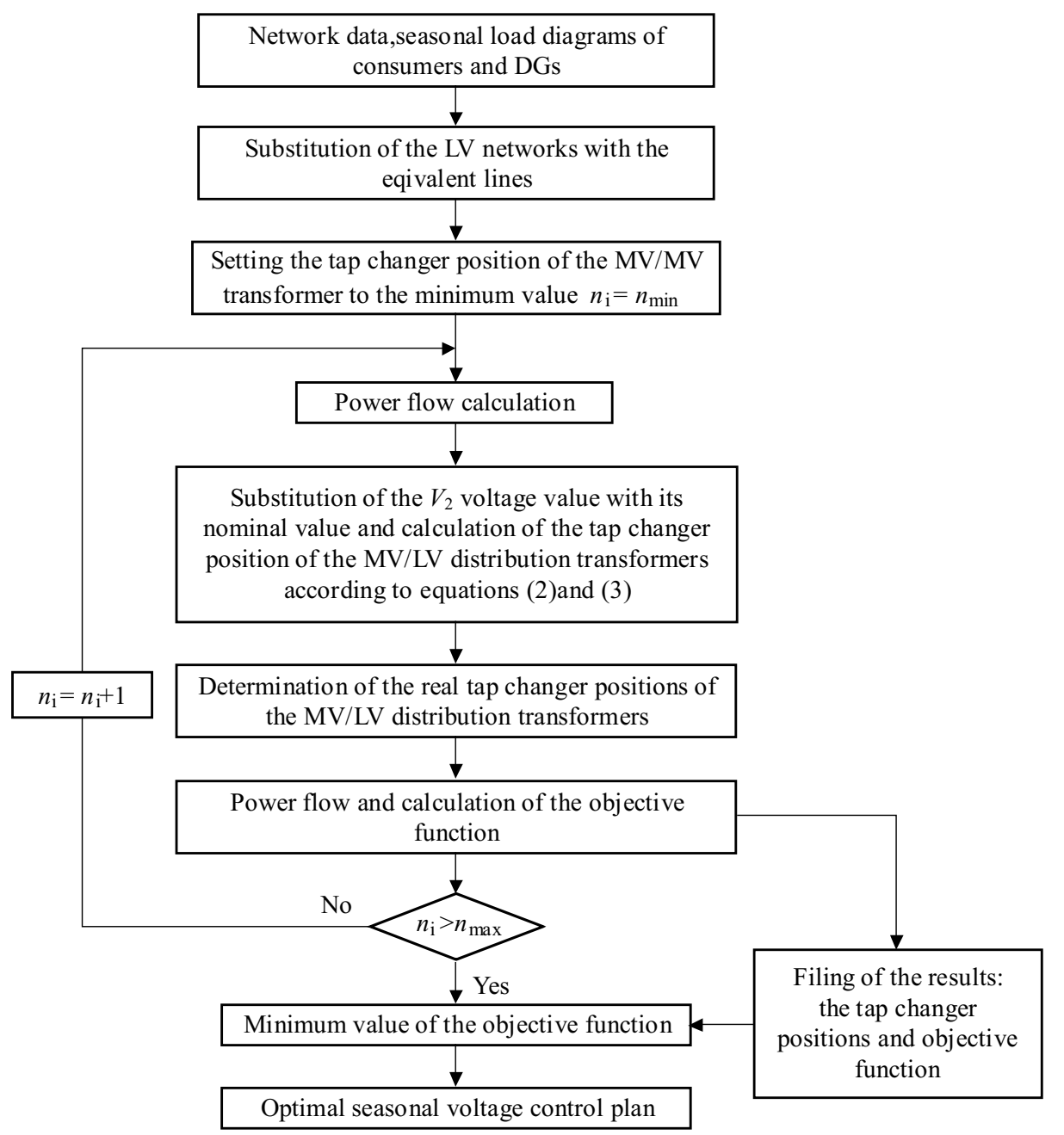

Fig. 5. The optimal seasonal voltage control plan determination procedure flowchart

following

$\mathcal{Z}_{i}$-the impedance of the $i^{\text {th }}$ section of the radial LV line, $i=1,2, \ldots, N$

$\mathcal{S}_{i}$-the injection power at the node $i$ of the radial $\mathrm{LV}$ line

$\mathcal{V}_{i}$-the voltage at the node $i$ of the radial LV line

$\mathcal{Z}_{e j}$-the equivalent model impedance of the $j^{\text {th }}$ radial LV line, $j=1,2, \ldots, M$

$\mathcal{S}_{e j}$-the equivalent model injection power of the $j^{\text {th }}$ radial LV line

$\mathcal{V}_{e j}$-the equivalent model voltage of the $j^{\text {th }}$ radial LV line

$\mathcal{Z}_{e}$-the equivalent model impedance of the $M$ radial LV lines, (LV network)

$\mathcal{S}_{e}$-the equivalent model injection power of the $M$ radial LV lines

\subsection{The second stage of the optimal seasonal voltage control}

Determining the tap changer position of the $\mathrm{MV} / \mathrm{MV}$ supply transformer represents the second stage of the procedure for solving the problem of the optimal seasonal voltage control. Simultaneously with the voltage limita- tion criteria, it is also necessary to satisfy a certain optimisation criterion while solving this problem. The mentioned criterion can be the loss minimization, voltage sag minimization or damage minimization due to the voltage deviation from the referring (nominal) value $[18,19]$. The objective function, to be minimized, can be expressed through the following equation [19]

$$
\text { ObjFun }=\min \Delta V=\min \sqrt{\sum_{i=1}^{N_{n}}\left(V_{\text {ref }}-V_{i}\right)^{2}},
$$

Where $V_{i}$ is the voltage at the $i$ node of the distribution network, $V_{\text {ref }}$ is the referent (nominal) voltage value, and $N_{n}$ is the number of the distribution network nodes.

Carrying out this optimization task is brought down to the power flow calculation for all possible tap changer positions of the supply transformer. During each power flow calculation, the tap changer positions of the MV/LV transformers are determined for the current tap changer position of the supply $\mathrm{MV} / \mathrm{LV}$ transformer according to the procedure described in 2.1. At the same time, the value of the objective function (12) is calculated. The minimum value of the objective function implicates the 


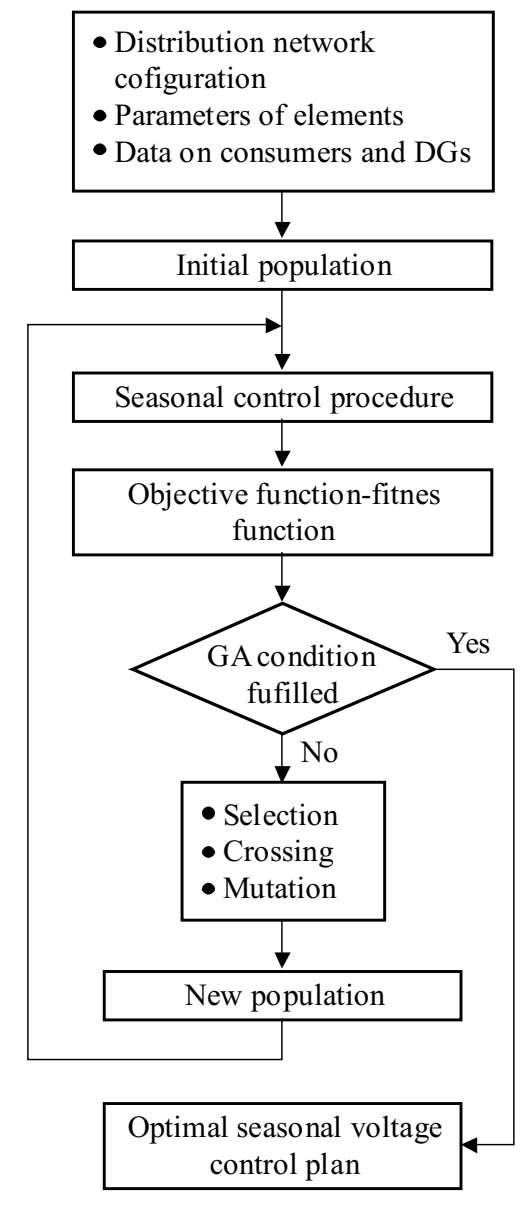

Fig. 6. Simplified flowchart of the seasonal voltage control course with the PV nodes taken into consideration

optimal solution, ie the optimal seasonal control plan of the distribution transformers in the given distribution network. The adopted optimization criterion determines the control plan. The flowchart of the proposed procedure is given in Fig. 5.

The optimal seasonal control plan determination procedure should be applied:

a) On regular basis, once a year, based on the updated load diagrams from the current year.

b) Extraordinarily, after significant changes in the distribution network that have occurred, such as: adding a new DG unit, network reconstruction by building a new line, transformer etc.

\subsection{Treatment of the PV nodes}

DG modelled as PV node operate with the constant active power and constant voltage module. The influence, that the power change in the distribution network has on the PV node voltage, is compensated by changing the reactive power injection of the PV node (DG). In this way, the PV node voltage is kept at the given (specified) value. This means that the voltage module values of the PV nodes can be subject to choosing or setting up independently within a certain range. The mentioned

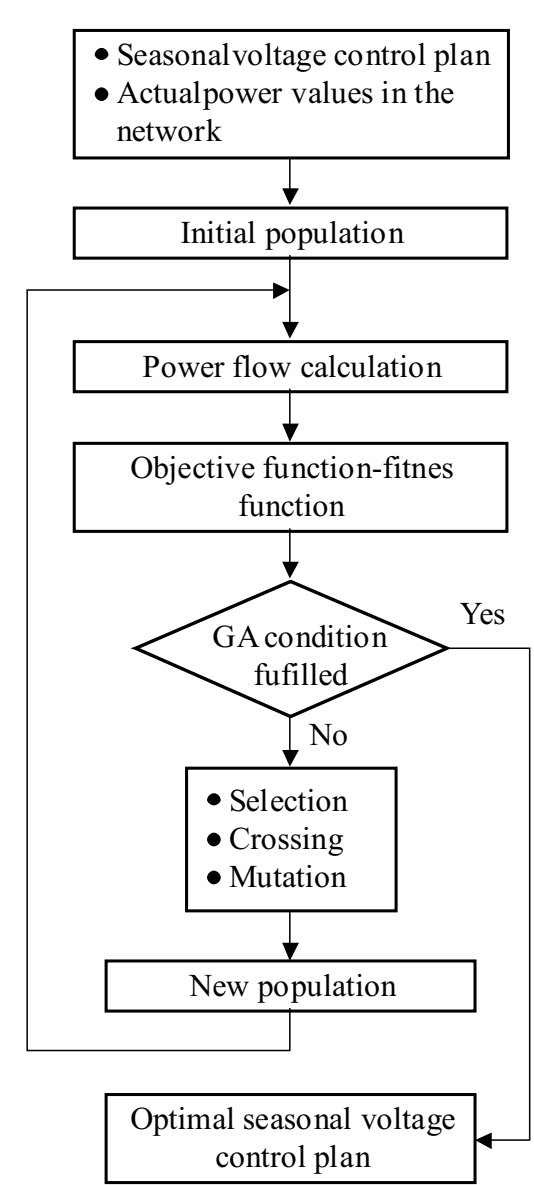

Fig. 7. Simplified flowchart of the algorithm for the voltage correction at $\mathrm{PV}$ nodes

range is determined by the active power and a possible range of the reactive power alteration of the DG for the given condition in the distribution network. Then, the optimal voltage module values of PV nodes in the optimal seasonal voltage control plan should be determined. This can be solved by the application of the genetic algorithm (GA), which means that the optimal seasonal control plan determination procedure (Fig. 5) is carried out for different voltage values (combinations) of the PV nodes, whilst those values are selected in the GA according to the given objective function. The GA operations $[20]$ are implemented by MATLAB $\AA$ toolbox gads software module in the MATLAB R2007a. Fig. 6 shows the simplified flowchart for determining the optimal seasonal voltage control plan with the PV nodes taken into consideration.

In this case, the optimal seasonal voltage control plan implies the optimal tap changer positions of the OVTCT as well as optimal voltage values of the PV nodes (DG).

\section{VOLTAGE CORRECTION AT THE PV NODES}

The optimal seasonal voltage control plan is defined for the mean power values over the given period. The 


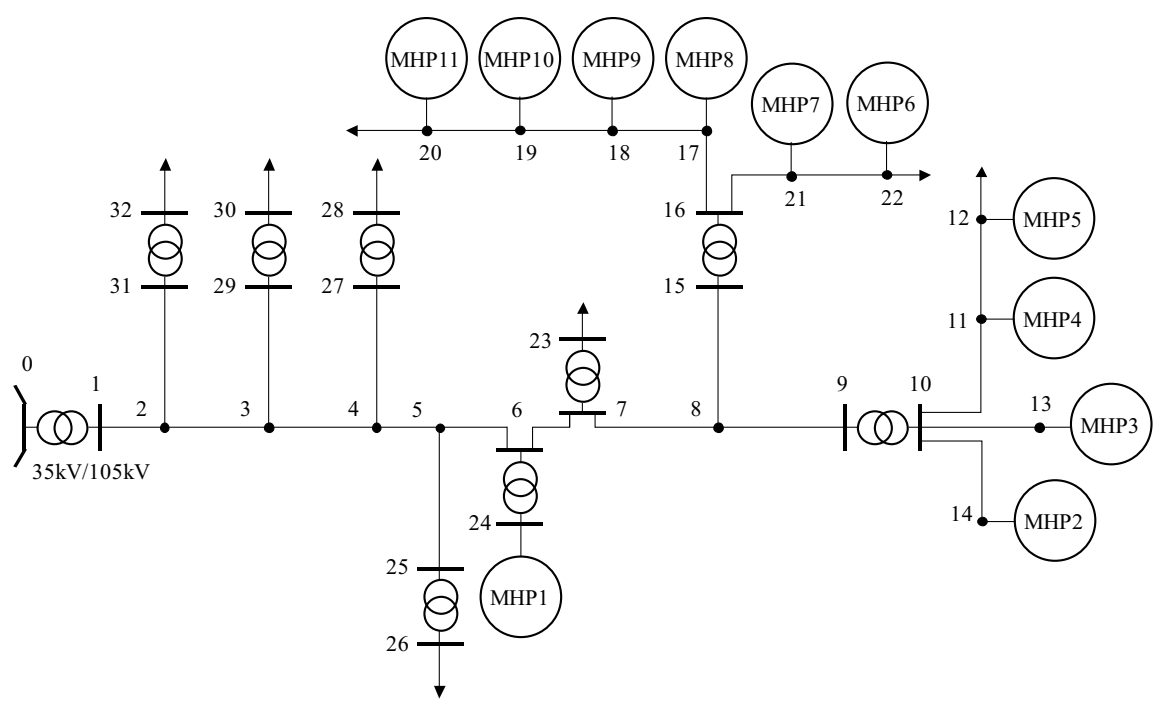

Fig. 8. 33-node distribution network

Table 1. Equivalent model impedances and injection powers of the LV networks

\begin{tabular}{cccccc}
\hline \multicolumn{2}{c}{ LV network } & \multicolumn{2}{c}{ January-June } & \multicolumn{2}{c}{ July-December } \\
TF & nodes & $\mathcal{Z}_{e}(\mathrm{pu})$ & $\mathcal{S}_{e}(\mathrm{pu})$ & $\mathcal{Z}_{e}(\mathrm{pu})$ & $\mathcal{S}_{e}(\mathrm{pu})$ \\
\hline $9-10$ & $11,12,13,14$ & $1.8899+j 0.4162$ & $-0.0408+j 0.0243$ & $5.6586+j 1.2793$ & $-0.004+j 0.0193$ \\
$15-16$ & $17,18,19,20,21,22$ & $1.9149+j 0.5245$ & $-0.0456+j 0.0283$ & $2.0187+j 0.5035$ & $-0.0136+j 0.0231$ \\
\hline
\end{tabular}

voltage correction at the PV nodes implies determining the optimal voltage values of the PV nodes in accordance with the actual load powers. It starts from the optimal seasonal voltage control plan, and the optimal voltage values of the PV nodes are determined by applying the GA for the actual load power and active power of the PV nodes. The objective function is the same as when determining the optimal seasonal control plan (Equation 12). Figure 7 shows the simplified flowchart for the voltage correction at the PV nodes.

\section{CASE STUDIES}

The proposed procedures is applied in two real distribution networks, whose are located in the east of Serbia.

\subsection{Case study: 33-node distribution network}

Figure 8 shows a rural distribution network containing 11 DGs. Those DGs are micro-hydro power plants (MHPs). The MV network is supplied through an OVTCT $(35 \pm 2 \cdot 2.5 \%) / 10 \mathrm{kV} / \mathrm{kV}$. The MV network supplies eight MV/LV OVTCTs $(10 \pm 2 \cdot 2.5 \%) / 0.4 \mathrm{kV} / \mathrm{kV}$. The data regarding the lines, transformers and consumers is given in the Appendix (Table A1). Figure 9 shows the annual power diagram of the DGs (MHPs).
It is possible to identify two typical periods in the power diagrams of the DGs: the period of the higher power (January-June) and the period of the lower power (July-December). Therefore, it has been agreed to apply the procedure to these two periods - seasons. At the same time, the mean values of the MHP powers have been taken into consideration during the two seasons. It is assumed that the consumers' powers are constant, due to the fact that this rural area has low power and its changes are slight during the year. We also assume that the value of voltage $V_{2}$ (Equation 2), $V_{\text {ref }}$ (Equation 12) and root node voltage is $1(\mathrm{pu})$.

The impedances and injection powers of the equivalent line models of the LV networks, which belong to transformers $9-10$ and 15-16, are shown in Tab. 1. The optimal seasonal voltage control plan is given in Tab. 2 . Figure 10 shows the network voltage profiles at the maximum and minimum simultaneous powers of all the DGs, in cases when the optimal seasonal control plan is applied and when there is no optimal seasonal control plan (neutral positions of the tap changers of all the transformers). Treatment of the voltage limits: values of the upper and lower voltage limits in the MV and LV networks are specified according to the engineering standards (eg 105 and $95 \%)[18]$.

Figure 10(a) clearly shows that by the correction of the voltage ratio at transformers 9,10 and $15-16$, in accordance with the optimal seasonal voltage control plan, 

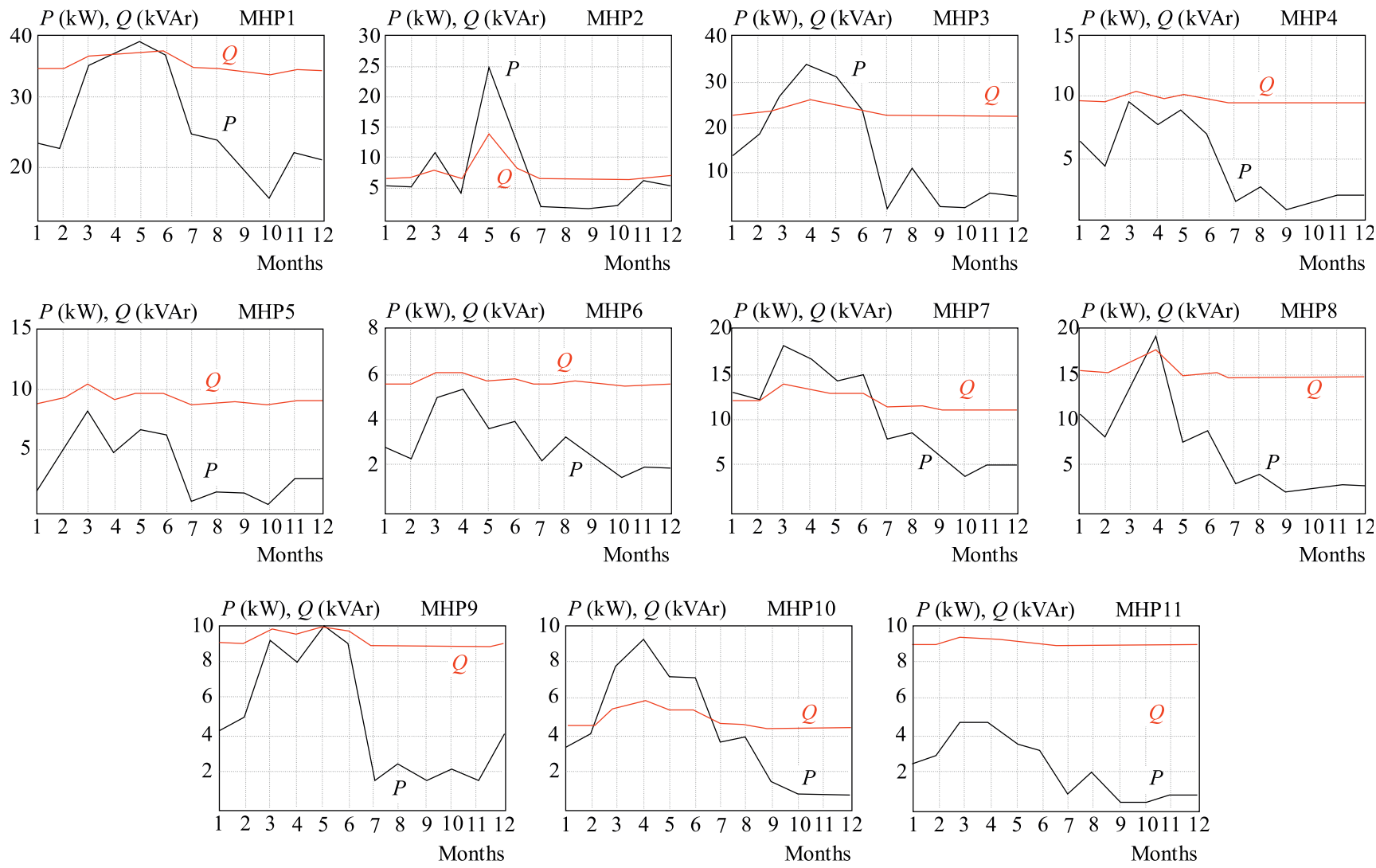

Fig. 9. Annual power diagram of the DGs
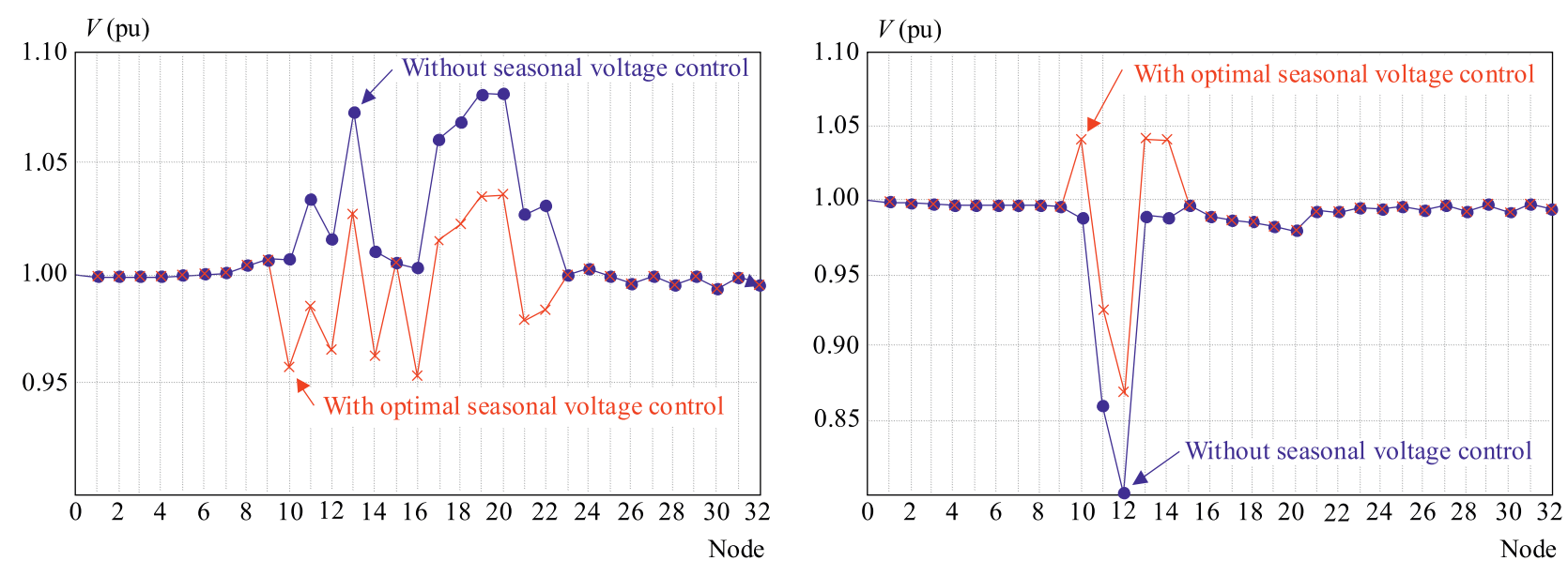

Fig. 10. The network voltage profiles without voltage control (all positions of tap changers are $n=0$ ) and with optimal seasonal voltage control. (a) For maximal (season January - Jun) coincidental MHPs power. (b) For minimal (season July - December) coincidental MHPs power

the voltage values decrease at nodes $13,17-20$ and are brought down to a range within the standard limits $(0.95 \mathrm{pu}-1.05 \mathrm{pu})$. In case the DG has the minimal simultaneous power (Fig. 10(b)), applying the optimal seasonal voltage control somewhat improves the voltage at nodes 11 and 12, but not enough since their values are still lower than the minimum allowed according to the standard (0.95). Nevertheless, in the given circumstances, this is the maximum improvement of the voltage profile, which implicates a limited domain of the seasonal voltage control.
Table 2. Optimal seasonal voltage control plan

Season: January - June

Transformer 9-10 $15-16 \begin{gathered}\text { Other } \\ \text { transformers }\end{gathered}$

Tap changer position $n_{r} \quad 2 \quad 2 \quad 2 \quad 0$

Season: July - December

Transformer $\quad 9-10$

Other

Tap changer position $n_{r} \quad-2$ transformers

0 


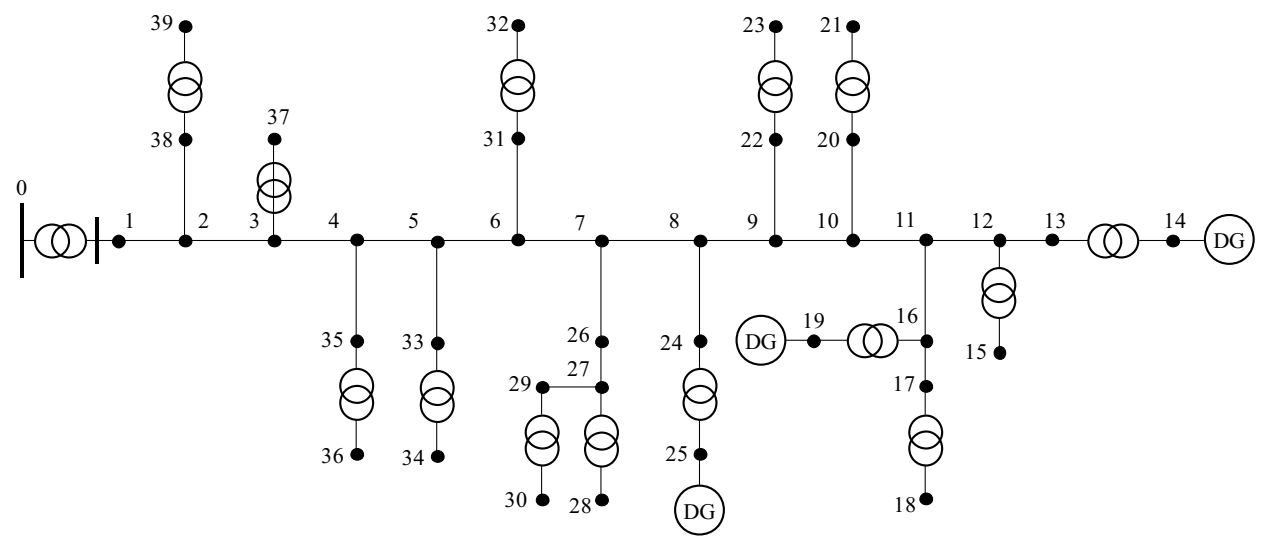

Fig. 11. 40-node distribution network

Table 3. Characteristics of the DGs

\begin{tabular}{ccccc}
\hline Node & Model & $P_{D G}(\mathrm{pu})$ & $Q_{D G}(\mathrm{pu})$ & $V(\mathrm{pu})$ \\
\hline 14 & $\mathrm{PV}$ & 0.2 & $-0.2 \div 0.2$ & $0.95 \div 1.05$ \\
25 & $\mathrm{PV}$ & 0.2 & $-0.2 \div 0.2$ & $0.95 \div 1.05$ \\
19 & $\mathrm{PQ}$ & 0.1 & $\cos \varphi=0.7$ & - \\
\hline
\end{tabular}

\subsection{Case study: 40-node distribution network}

In order to apply the optimal seasonal voltage control procedure with the $\mathrm{PV}$ nodes taken into consideration, as well as the correction of the voltage at the PV nodes, the network, as shown in Fig. 11, was used. In total 14 $\mathrm{MV} / \mathrm{LV}$ OVTCTs $(10 \pm 2 \cdot 2.5 \%) / 0.4 \mathrm{kV} / \mathrm{kV}$ were connected to the MV $(10 \mathrm{kV})$ network, which is supplied by the OVTCT $(35 \pm 2 \cdot 2.5 \%) / 10 \mathrm{kV} / \mathrm{kV}$. All the data regarding the impedances of the network branches, as well as the nominal power of the consumers are given in Table A2 in the Appendix. It has been assumed that all the consumers have the same normalized annual power diagram, which is shown in Fig. 12. The characteristics of the DG are given in Tab. 3. The DGs which provide constant active power and have the ability to control the reactive power and thereby voltage module are connected to nodes 14 and 25. The DG connected to node 19 injects constant active power with a constant power factor.

The optimal seasonal voltage control plan which is given in Tab. 4 has been determined for the mean power values shown in Fig. 12. Apart from the optimal tap changer positions of the transformers, the optimal voltage values of the PV nodes represent an integral part of the optimal seasonal voltage control plan.

As shown in Tab. 4, the optimal positions of the tap changers at the MV/LV OVTCTs are the same in both seasons, and they should not be alternated once they are set (assuming that the annual power diagram remains unchanged). In accordance with this, minimum actions are required in order to carry out the control plan (the position of the tap changer at the supply OVTCT, and specified voltage values of the DG at nodes 14 and 25 should be changed twice a year).

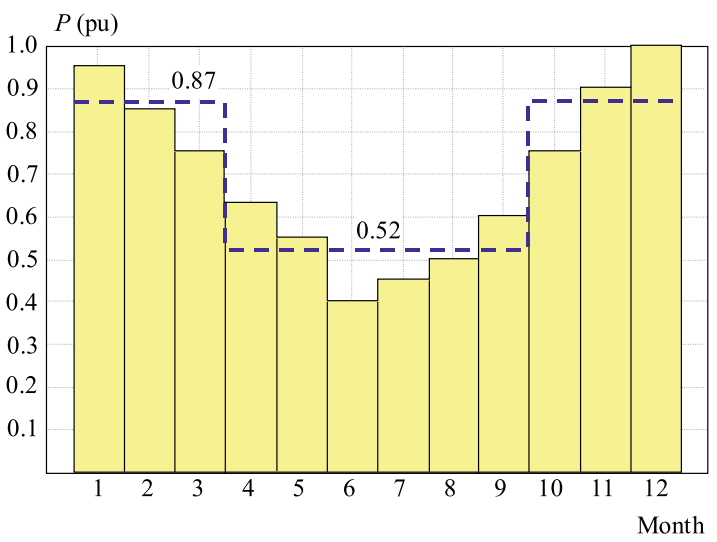

Fig. 12. Normalized annual power diagram of the consumers in a 40-node system

Table 4. Optimal seasonal voltage control plan

\begin{tabular}{ccc}
\hline & Oct-Mar & Apr-Sep \\
& $P=0.87$ & $P=0.52$ \\
\hline Transformer Tap changer & position, $n_{r}$ \\
\hline $0-1$ (Supply) & -1 & 0 \\
$13-14$ & -1 & -1 \\
$12-15$ & -1 & -1 \\
$17-18$ & -1 & -1 \\
$16-19$ & 0 & 0 \\
$20-21$ & -1 & -1 \\
$22-23$ & -1 & -1 \\
$24-25$ & 0 & 0 \\
$27-28$ & -1 & -1 \\
$29-30$ & -2 & -2 \\
$31-32$ & -2 & -2 \\
$33-34$ & -2 & -2 \\
$35-36$ & -1 & -1 \\
$3-37$ & -1 & -1 \\
$38-39$ & -1 & -1 \\
\hline DG & \multicolumn{2}{c}{ Voltage (pu) } \\
\hline 14 & 1.0388 & 1.0500 \\
25 & 0.9899 & 1.0304 \\
ObjFun (pu) & 0.0477 & 0.0295 \\
\hline
\end{tabular}

By the application of the voltage correction procedure at the PV nodes, the optimal (corrected) values of the 


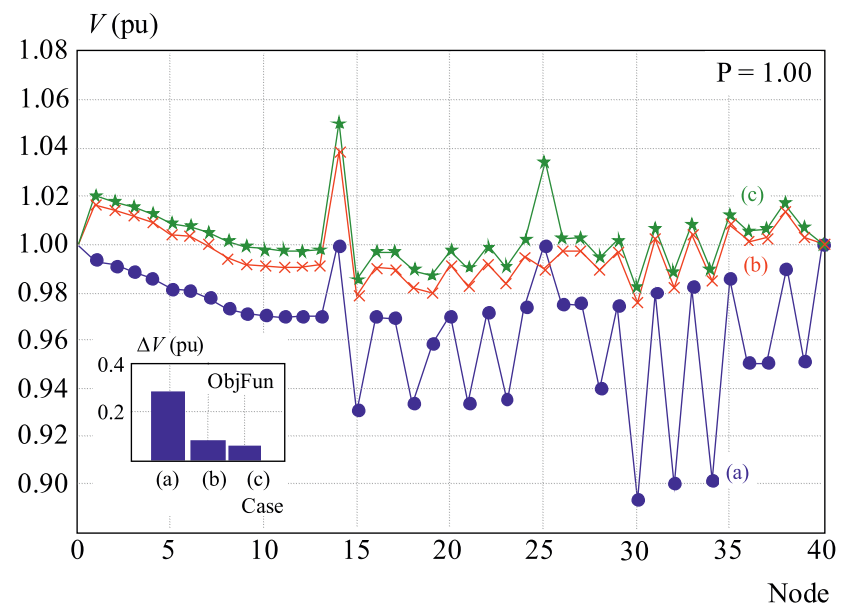

Fig. 13. The voltage profiles in 40-node distribution network for $\max (P=1.00)$ consumers power level: $(\mathrm{a})$ - without voltage control (all positions of the tap changers are $n=0$ and the PV node voltages are equal to $1,(\mathrm{~b})$ - with optimal seasonal voltage control and (c)- optimal seasonal voltage control with the correction of the $\mathrm{PV}$ node voltages

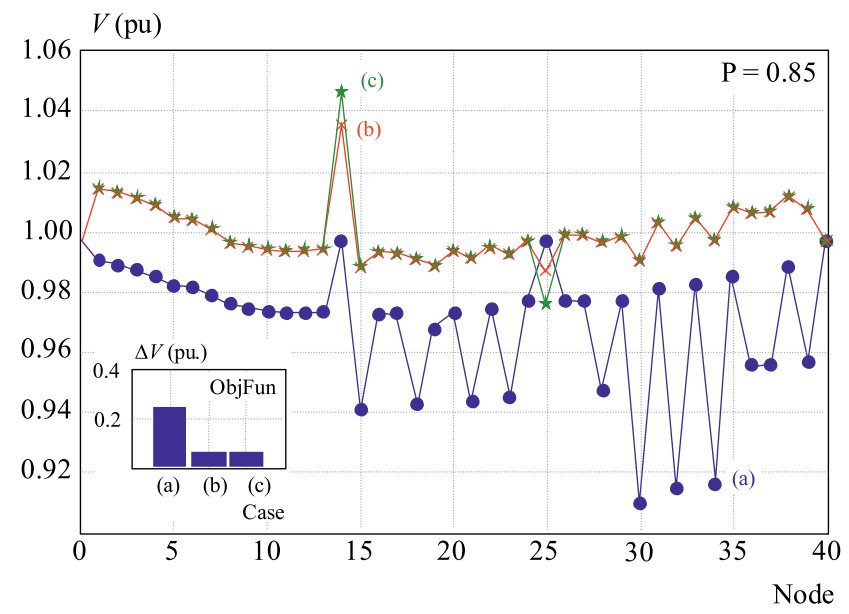

Fig. 15. The voltage profiles in 40-node distribution network for $P=0.85$ consumers power level: $(\mathrm{a})$ - without voltage control (all positions of the tap changers are $n=0$ and $\mathrm{PV}$ node voltages are equal to 1 , (b) - with optimal seasonal voltage control and (c)optimal seasonal voltage control with the correction of the PV node voltages

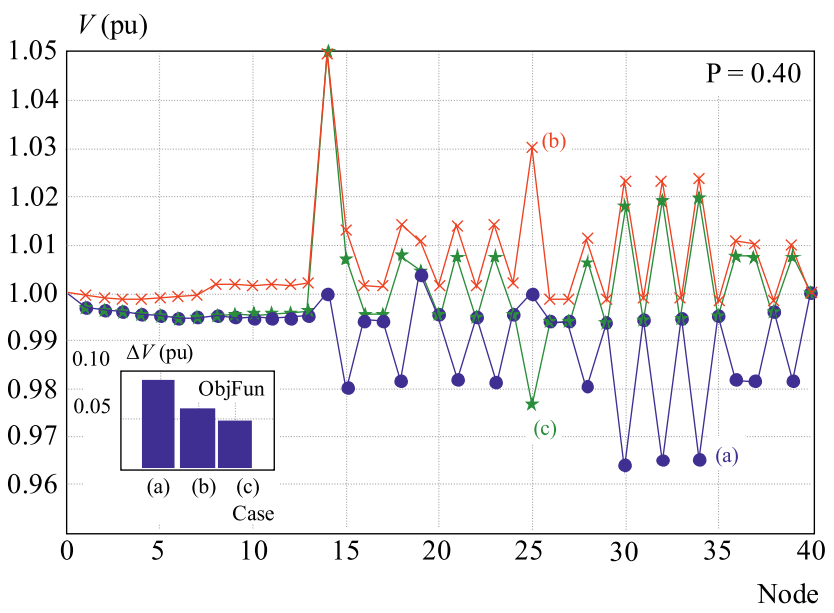

Fig. 14. The voltage profiles in 40-node distribution network for $\min (P=0.40)$ consumers power level. (a) - without voltage control (all positions of the tap changers are $n=0$ and PV node voltages are equal to 1) and (b) - with optimal seasonal voltage control, (c) optimal seasonal voltage control with the correction of the PV node voltages

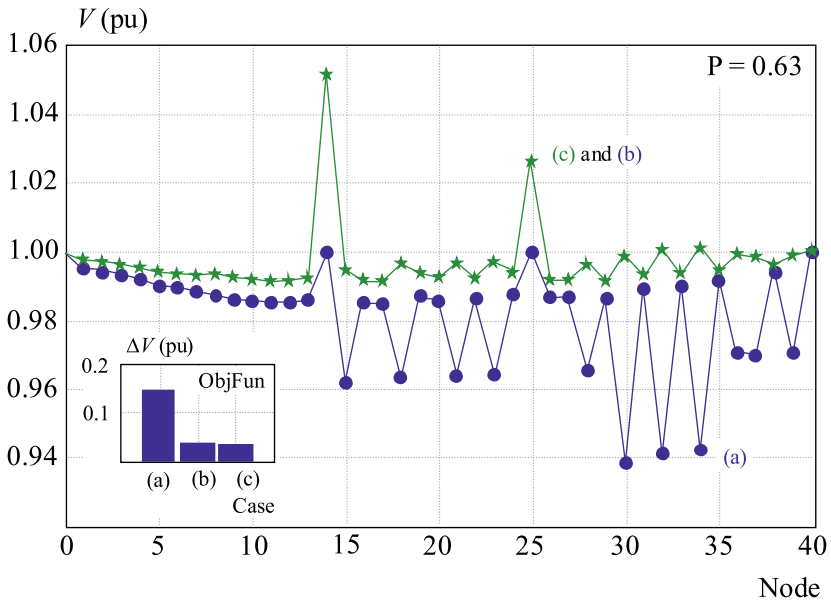

Fig. 16. The voltage profiles in 40 -node distribution network for $P=0.63$ consumers power level: (a) - without voltage control (all positions of tap changers are $n=0$ and $\mathrm{PV}$ node voltages are equal to 1 , (b) - with optimal seasonal voltage control, and (c) - optimal seasonal voltage control with the correction of the PV node voltages

Table 5. Optimal (corrected) voltages of the PV nodes

\begin{tabular}{lccccccccccc}
\hline & $P=1.00$ & $P=0.95$ & $P=0.90$ & $P=0.85$ & $P=0.75$ & $P=0.63$ & $P=0.60$ & $P=0.55$ & $P=0.50$ & $P=0.45$ & $P=0.40$ \\
\hline$V_{\text {DG14 }}(\mathrm{pu})$ & 1.0498 & 1.0492 & 1.0500 & 1.0492 & 1.0041 & 1.0485 & 1.0498 & 1.0500 & 1.0462 & 1.0445 & 1.0499 \\
$V_{\text {DG25 }}(\mathrm{pu})$ & 1.0351 & 1.0260 & 0.9990 & 0.9782 & 0.9791 & 1.0281 & 1.0305 & 1.0302 & 1.0271 & 1.0063 & 0.9766 \\
ObjFun $(\mathrm{pu})$ & 0.0569 & 0.0520 & 0.0487 & 0.0465 & 0.0467 & 0.0374 & 0.0305 & 0.0270 & 0.0325 & 0.0390 & 0.0458 \\
\hline
\end{tabular}

voltage at the PV nodes for all the power levels from the diagram in Fig. 12 have been determined. These are the voltages at nodes 14 and 25. The results are shown in Tab. 5. The corrected voltage values, especially at node 14 are quite close to the values from the optimal seasonal plan (Tab. 4). Figs. 13-16 show the voltage profiles and corresponding values of the objective functions for the typical power levels of the consumers (maximum, minimum and mean), in different voltage control cases.

The application of the optimal seasonal voltage control plan enables a significant improvement of the voltage profile of the network in the analyzed cases. The effect the voltage correction at the PV nodes has on the im- 
provement of the network voltage profile depends on the load power. As shown in Figs. 13 and 14, this effect is quite important at extreme load power values. At load power close to the mean power value in the given period (which is used when defining the seasonal control plan), this effect is rather small or even completely irrelevant, as shown in Fig. 16, where the voltage profiles have a complete match in cases (b) and (c).

\section{CONCLUSIONS}

The procedure for determining the optimal seasonal voltage control plan in rural distribution networks with DGs is presented and applied in this paper. The main characteristics of this procedure are:

- spatial decomposition principle of the voltage control problem,

- bringing down the LV network to the equivalent line with the aim to apply the optimal setting of the transfer ratio of $\mathrm{MV} / \mathrm{LV}$ distribution transformer,

- additional improvement of the network voltage profile by correcting the voltage at PV nodes by applying the GA.

The case studies have shown the practical application of the described procedure in the distribution networks with a larger number of DGs modelled as PQ and PV nodes.

The application of the procedure on a real 33-node distribution network with DGs modelled as PQ nodes has shown the following:

- The outstanding variation of the generated power during the year and a significant space dispersion of the MHPs caused the voltage variation out of the standard limits.

- The optimal model of the seasonal voltage control at transformers enables the control of the voltage values within the standard limits, except for some outlying nodes.

The application of the procedure on the 40-node distribution network with the DGs modelled as PQ and PV nodes has shown that the optimal voltage correction of the PV nodes enables an additional improvement of the network voltage profile compared to the seasonal voltage control at transformers.

\section{REFERENCES}

[1] BARKER, P. P.—De MELLO, R. W. : Determining the Impact of Distributed Generation on Power Systems. I. Radial Distribution Systems, In: Proc. Of the Power Engineering Society Summer Meeting IEEE, vol. 3, pp. 1645-1656.

[2] El-KhatTAM, W.-SAlAmA, M. M. A.: Distributed Generation Technologies, Definitions and Benefits, Electric Power System Research $\mathbf{7 1}$ (2004), 119-128.

[3] CAIRE, R.-RETIERE, N.-MARTINO, S.-ANDRIEU, C. - HADJSAID, N. : Impact Assessment of LV Distributed Generation on MV Distribution Network, In: Proc. Of the Power Engineering Society Summer Meeting IEEE, vol. 3, pp. 1423-1428.
[4] TRAN-QUOC, T.-ANDRIEU, C.-HADJSAID, N.: Technical Impacts of Small Distributed Generation Units on LV Networks, In: Proc. Of the Power Engineering Society General Meeting IEEE, vol. 4, pp. 2459-2464.

[5] BORGES, C. L. T.-FALCAO, D. M. : Impact of Distributed Generation Allocation and Sizing on Reliability, Losses and Voltage Profile, In: Proc. Of the Power Tech Conference Proceedings IEEE, vol. 2, p. 5 .

[6] BAGHzOUZ, Y.: Some General Rules for Distributed Generation - Feeder Interaction, In: Proc. Of the Power Engineering Society General Meeting IEEE, p. 4.

[7] GREATBAnKS, J. A.-POPOVIC, D. H.-BEGOViĆ, M.PREGELJ, A.-GREEN, T. C. : On Optimization for Security and Reliability of Power Systems with Distributed Generation, In: Proc. Of the Bologna Power Tech Conference IEEE, vol. 1, p. 8.

[8] BORGES, C. L. T.-FALCAO, D. M.: Optimal Distributed Generation Allocation for Reliability, Losses and Voltage Improvement, International Journal of Electrical Power \& Energy Systems 28 (2006), 413-420.

[9] CHOI, J. H.-KIM, J. C.: Advanced Voltage Control Method of Power Distribution System Interconnected with Dispersed Storage and Generation System, IEEE Trans. On Power Delivery 16 (2001), 329-334.

[10] KIM, T. E.-KIM, J. E.: Voltage Control Coordination of Distributed Generation System in Distribution System, In: Proc. Of the Power Engineering Society Summer Meeting IEEE, vol. 1, pp. $480-484$.

[11] KOJOVIC, L.: Impact of DG on Voltage Control, In: Proc. Of the Power Engineering Society Summer Meeting IEEE, vol. 1, pp. 97-102.

12] NIKNAM, T.-RANJBAR, A. M.-SHIRANI, A. R. : Impact of Distributed Generation on Volt/Var Control in Distribution Networks, In: Proc. Of the Power Tech Conference Proceedings IEEE, vol. 3, p. 7 .

[13] KOJOVIC, L.: Coordination of Distributed Generation and Step Voltage Regulator Operations for Improved Distribution System Voltage Control, In: Proc. Of the Power Engineering Society General Meeting IEEE, p. 6.

[14] KATIRAEI, F.-ABBEY, C.-BAHRY, R. : Analysis of Voltage Control Problem for a 25-kV Distribution Network with Distributed Generation, In: Proc. Of the Power Engineering Society General Meeting IEEE, p. 8.

15] BIGNUCOLO, F.-CALDON, R.-PRANDONI, V.: Radial MV Networks Voltage Control with Distribution Management System Coordinated Controller, Electric Power System Research 78 (2008), 634-645.

16] FERRY, V. A.-AMBRA, S.-JAAP, D. : Voltage Control with On-Load Tap Changers in Medium Voltage Feeders in Presence of Distributed Generation, Electric Power Systems Research 77 (2007), 1314-1322.

[17] CHENG, C. S.-SHIRMOHAMmADI, D.: A Three-Phase Power Flow Method for Real-Time Distribution System Analysis, IEEE Trans. Power Systems 10 (1995), 671-679.

[18] STREzOSKI, V. S.-KATIC, N. A.-JANJIC, D. S. : Voltage Control Integrated in Distribution Management System, Electric Power Systems Research 60 (2001), 85-97.

19] MENDOZA, J. E.-MORALES, D. A.-LOPEZ, R.-LOPEZ, E. A.-VANNIER, J. C.-COELLO, C. A. : Multiobjective Location of Automatic Voltage Regulators in a Radial Distribution Network using a Micro Genetic Algorithm, IEEE Transactions on Power Systems 22 (2000), 404-412.

[20] LEE, K. Y.-El-SHARKAWI, M. A.: Tutorial on Modern Heuristic Optimization Techniques with Applications to Power Systems, IEEE Power Engineering Society, IEEE Catalog Number 02TP160, 2002.

Received 23 November 2009 


\section{Appendix}

Table A1 Branch and load parameters of the 33-node distribution system*

\begin{tabular}{|c|c|c|c|c|c|c|}
\hline \multicolumn{2}{|c|}{ Branch } & \multirow{2}{*}{$\begin{array}{c}R \\
(\mathrm{pu}) \\
\end{array}$} & \multirow{2}{*}{$\begin{array}{c}X \\
(\mathrm{pu})\end{array}$} & \multirow[t]{2}{*}{ Node } & \multirow{2}{*}{$\begin{array}{c}P_{L} \\
(\mathrm{pu})\end{array}$} & \multirow{2}{*}{$\begin{array}{c}Q_{L} \\
(\mathrm{pu})\end{array}$} \\
\hline$i$ & $j$ & & & & & \\
\hline 0 & 1 & 0.0021 & 0.0149 & 1 & & \\
\hline 1 & 2 & 0.0083 & 0.0068 & 2 & 0 & 0 \\
\hline 2 & 3 & 0.0066 & 0.0054 & 3 & 0 & 0 \\
\hline 3 & 4 & 0.0072 & 0.0060 & 4 & 0 & 0 \\
\hline 4 & 5 & 0.0027 & 0.0022 & 5 & 0 & 0 \\
\hline 5 & 6 & 0.0145 & 0.0119 & 6 & 0 & 0 \\
\hline 6 & 7 & 0.0010 & 0.0009 & 7 & 0 & 0 \\
\hline 7 & 8 & 0.0376 & 0.0077 & 8 & 0 & 0 \\
\hline 8 & 9 & 0.0517 & 0.0106 & 9 & 0 & 0 \\
\hline 9 & 10 & 0.2000 & 0.3464 & 10 & 0 & 0 \\
\hline 10 & 11 & 10.5262 & 3.2725 & 11 & 0 & 0 \\
\hline 11 & 12 & 5.2631 & 1.6362 & 12 & 0.0074 & 0.0036 \\
\hline 10 & 13 & 2.6316 & 0.8181 & 13 & 0 & 0 \\
\hline 10 & 14 & 0.2256 & 0.0701 & 14 & 0 & 0 \\
\hline 8 & 15 & 0.0451 & 0.0093 & 15 & 0 & 0 \\
\hline 15 & 16 & 0.2000 & 0.3464 & 16 & 0 & 0 \\
\hline 16 & 17 & 3.1579 & 0.9818 & 17 & 0 & 0 \\
\hline 17 & 18 & 0.5263 & 0.1636 & 18 & 0 & 0 \\
\hline 18 & 19 & 1.5789 & 0.4909 & 19 & 0 & 0 \\
\hline 19 & 20 & 0.8271 & 0.2571 & 20 & 0.0014 & 0.0007 \\
\hline 16 & 21 & 1.8045 & 0.5610 & 21 & 0 & 0 \\
\hline 21 & 22 & 2.3308 & 0.7246 & 22 & 0.0008 & 0.0004 \\
\hline 7 & 23 & 0.2000 & 0.3464 & 23 & 0.0028 & 0.0014 \\
\hline 6 & 24 & 0.2000 & 0.3464 & 24 & 0 & 0 \\
\hline 5 & 25 & 0.0199 & 0.0117 & 25 & 0 & 0 \\
\hline 25 & 26 & 0.2000 & 0.3464 & 26 & 0.0096 & 0.0041 \\
\hline 4 & 27 & 0.0024 & 0.00075 & 27 & 0 & 0 \\
\hline 27 & 28 & 0.2000 & 0.3464 & 28 & 0.0126 & 0.0054 \\
\hline 3 & 29 & 0.0042 & 0.0013 & 29 & 0 & 0 \\
\hline 29 & 30 & 0.2000 & 0.3464 & 30 & 0.0178 & 0.0076 \\
\hline 2 & 31 & 0.0120 & 0.0037 & 31 & 0 & 0 \\
\hline 31 & 32 & 0.2000 & 0.3464 & 32 & 0.0099 & 0.0042 \\
\hline
\end{tabular}

*Resistances, reactance and power values are given in perunit system (pu) and were calculated for the basic values of power 1 MVA and voltages: $10 \mathrm{kV}$ and $0.4 \mathrm{kV}$.

Table A2 Branch and load parameters of the 40-node distribution system*

\begin{tabular}{ccccccc}
\hline \multicolumn{2}{c}{ Branch } & $R$ & $X$ & Node & $P_{L}$ & $Q_{L}$ \\
$i$ & $j$ & $(\mathrm{pu})$ & $(\mathrm{pu})$ & & $(\mathrm{pu})$ & $(\mathrm{pu})$ \\
\hline 0 & 1 & 0.0010 & 0.0074 & 1 & 0 & 0 \\
1 & 2 & 0.0010 & 0.0006 & 2 & 0 & 0 \\
2 & 3 & 0.0011 & 0.0006 & 3 & 0 & 0 \\
3 & 4 & 0.0027 & 0.0016 & 4 & 0 & 0 \\
4 & 5 & 0.0043 & 0.0025 & 5 & 0 & 0 \\
5 & 6 & 0.0011 & 0.0006 & 6 & 0 & 0 \\
6 & 7 & 0.0040 & 0.0024 & 7 & 0 & 0 \\
7 & 8 & 0.0083 & 0.0049 & 8 & 0 & 0 \\
8 & 9 & 0.0029 & 0.0017 & 9 & 0 & 0 \\
9 & 10 & 0.0018 & 0.0011 & 10 & 0 & 0 \\
10 & 11 & 0.0006 & 0.0004 & 11 & 0 & 0
\end{tabular}

\begin{tabular}{ccccccc}
11 & 12 & 0.0007 & 0.0004 & 12 & 0 & 0 \\
12 & 13 & 0.0018 & 0.0010 & 13 & 0 & 0 \\
13 & 14 & 0.0343 & 0.1400 & 14 & 0 & 0 \\
12 & 15 & 0.0344 & 0.1357 & 15 & 0.360 & 0.170 \\
11 & 16 & 0.0019 & 0.0008 & 16 & 0 & 0 \\
16 & 17 & 0.0016 & 0.0003 & 17 & 0 & 0 \\
17 & 18 & 0.1172 & 0.2208 & 18 & 0.144 & 0.070 \\
16 & 19 & 0.0688 & 0.1533 & 19 & 0.225 & 0.109 \\
10 & 20 & 0.0004 & 0.0002 & 20 & 0 & 0 \\
20 & 21 & 0.2000 & 0.3464 & 21 & 0.090 & 0.043 \\
9 & 22 & 0.0012 & 0.0007 & 22 & 0 & 0 \\
2 & 23 & 0.2000 & 0.3464 & 23 & 0.090 & 0.043 \\
8 & 24 & 0.0015 & 0.0009 & 24 & 0 & 0 \\
24 & 25 & 0.0344 & 0.1357 & 25 & 0 & 0 \\
7 & 26 & 0.0105 & 0.0033 & 26 & 0 & 0 \\
26 & 27 & 0.0006 & 0.0002 & 27 & 0 & 0 \\
27 & 28 & 0.2000 & 0.3464 & 28 & 0.090 & 0.043 \\
26 & 29 & 0.0077 & 0.0033 & 29 & 0 & 0 \\
29 & 30 & 0.4800 & 0.6400 & 30 & 0.090 & 0.043 \\
6 & 3 & 0.00721 & 0.0022 & 31 & 0 & 0 \\
31 & 32 & 0.4800 & 0.6400 & 32 & 0.090 & 0.043 \\
5 & 33 & 0.0011 & 0.0006 & 33 & 0 & 0 \\
33 & 34 & 0.4800 & 0.6400 & 34 & 0.090 & 0.043 \\
4 & 35 & 0.0048 & 0.0015 & 35 & 0 & 0 \\
35 & 36 & 0.2000 & 0.3464 & 36 & 0.090 & 0.043 \\
3 & 37 & 0.0344 & 0.1357 & 37 & 0.360 & 0.170 \\
2 & 38 & 0.0021 & 0.0012 & 38 & 0 & 0 \\
38 & 39 & 0.0344 & 0.1357 & 39 & 0.360 & 0.170 \\
\hline & & & & & & \\
& & & & 0
\end{tabular}

*The values of the parameters and powers are given for the base values: $1 \mathrm{MVA}$ and $10 \mathrm{kV}$.

Jordan Radosavljević was born in Serbia in 1973. He received his BSc degree in 1998 from the Faculty of Electrical Engineering, University of Priština, MSc degree in 2003 from the Faculty of Electrical Engineering, University of Belgrade and $\mathrm{PhD}$ degree in 2009 from the Faculty of Technical Sciences, Priština University in Kosovska Mitrovica. His main research interests include power system analysis, electric power distribution and distributed power generation. Currently, he is a Research Assistant with the Faculty of Technical Sciences, University of Priština in Kosovska Mitrovica.

Miroljub Jevtić was born in Serbia in 1950. He received his BSc and MSc degrees in 1980 and 1987 from the Faculty of Electrical Engineering, University of Skopje, and two PhD degrees in 1989 and 1991, first from the Saint Petersburg State Polytechnic University, Russia, and second from the Faculty of Electrical Engineering, University of Skopje, Macedonia. His main research interests include power cable engineering, electrical insulations and distributed power generation. Currently, he is a Full Professor with the Faculty of Technical Sciences, University of Priština in Kosovska Mitrovica.

Dardan Klimenta was born in Serbia in 1975. He received his BSc degree in 1998 from the Faculty of Electrical Engineering, University of Priština, and $\mathrm{MSc}$ and $\mathrm{PhD}$ degrees in 2001 and 2007 from the Faculty of Electrical Engineering, University of Belgrade. His main research interests include application of finite element method to power cable engineering, electric power distribution and distributed power generation. Currently, he is an Assistant Professor with the Faculty of Technical Sciences, University of Priľstina in Kosovska Mitrovica. 